\title{
Update on the Canadian Institutes of Health Research: Where will respiratory health research fit in?
}

\author{
Malcolm King, PhD, President, Canadian Thoracic Society
}

$\mathrm{M}$ y main focus as Canadian Thoracic Society (CTS) President has been on research. The centre of attention has, of course, been the soon-to-be-established Canadian Institutes of Health Research (CIHR) and our Society's efforts to establish a position for respiratory research within this new organization.

Starting last April, around the time of the American Thoracic Society meeting, I coordinated a meeting of respiratory and critical care researchers in San Diego, California to discuss our society's position and our strategy in bringing our position forward. Dr Nicholas Anthonisen, of the University of Manitoba, Winnipeg, Manitoba, drafted a document describing an institute for respiratory and critical care health research that was widely circulated among our membership and modified according to the many suggestions sent to Dr Anthonisen or myself. On behalf of the Society, I submitted this document to the CIHR interim governing council in May 1999, where it formed part of a large number of submissions for possible research institutes. In July 1999, I prepared an application to the Medical Research Council to hold a symposium on respiratory and critical care research as part of a CIHR opportunities competition. The proposal was not funded, but based on the comments received and the valuable input from a number of our members as well as from our sister professional societies, I resubmitted the application for the October competition. The decision is still pending.

Also in the summer, partly to deal with the proposed conference, and at the request of Canadian Lung Association (CLA) President Gary Lathan, I established a CIHR action group to advise the CLA on matters relating to the CIHR. This group has met once, in person, in Montreal at the time of the Royal College meeting and our annual general meeting. The group also 'meets' on a frequent basis by electronic correspondence, and has responded to a number of issues and submissions that I have presented to them. The major issues have been the revised proposal to hold a national forum on respiratory and critical care health research, and the preparation of a position paper on a slate of institutes, in response to the request for input from the CIHR interim governing council.
Our document proposed a full slate of institutes, according to the CIHR request, including a Lung Health Institute.

Our slate of institutes proposal is a plea for a CIHR institute model that is at least partially based on what we have now - an organ and/or disease-based structure. The idea was to be innovative where it is needed, but not to

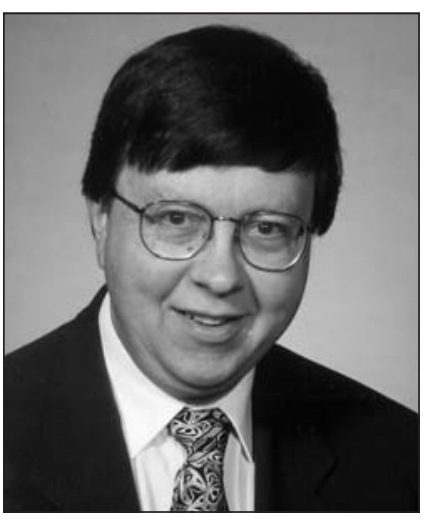
tear down existing structures just for the sake of innovation. In developing our document, in addition to the overall institute design, as the representatives of the respiratory research community, we were concerned with the specific issues of the numbers of researchers in the various disciplines of respiratory and critical care medicine, and where lung health research fit in within the overall slate of institutes. This position paper was circulated to the CLA action committee on CIHR, as well as to representatives from all the major pulmonary research groups in Canada. I received many excellent comments and suggestions from this community of researchers, and the resulting document is a synthesis of their contributions.

Finally, the respiratory community needs to be aware that many other models for CIHR structure have been submitted, notably those by the major universities and the National Voluntary Health Agencies (NVHA). In almost all of these proposals, respiratory research has been linked in some direct fashion with cardiovascular research, either alone or in larger groupings that include cerebrovascular, blood and even kidney research. Thus, the reality is that the most likely institute grouping that will include research on respiratory health is one that links us with cardiovascular and/or cerebrovascular topics. We (the CTS and the CLA) have received overtures from the Heart \& Stroke Foundation of Canada (HSFC) and the Canadian Cardiovascular Society (CCS) to join with them in designing a CIHR institute that would include car- 
diovascular and/or cerebrovascular and respiratory research. Accordingly, the HSFC and CCS organized a meeting in Ottawa, January 22 to 23, 2000, and invited a small delegation from the respiratory community to participate (Dr Carolyn Ross of the Canadian Nurses Respirtory Society, Dr Yves Berthiaume, substituting for CTS President-elect Dr Louis Phillipe-Boulet, and myself, representing the CTS; and Valoree McKay and Gary Lathan of the CLA). The meeting addressed a number of general issues, including the weaknesses and strengths of the proposed NVHA slate, which included an institute for circulation and respiration research; principles and parameters for partnering; institute design criteria; and issues of leadership and governance.

There was a general consensus among the HSFC and/or CCS attendees that a broad-based institute was preferable to a narrower one. The strengths of a large, cross-sectional institute were generally those of scale - critical mass of expertise, larger voice in the CIHR and a larger percentage of CIHR resources. A broad-based institute would also provide new opportunities for interactions and the sharing of expertise and resources. Drawbacks to a large, broad-based institute include the diminished identification with familiar institutions such as the HSFC and CLA, more cumbersome strategic planning, and greater difficulties in choosing the scientific director and advisory board. These concerns would be somewhat alleviated by a divisionalized institute structure, but at the expense of the economies of scale.

A draft institute proposal from the HSFC and/or CCS conference is currently being circulated to the CTS Board and the CIHR action group for discussion and comment. The respiratory research community will need to establish a position on this document, and to develop strategies to make our views known to the medical research community at large. Unfortunately, the CIHR is evolving very rapidly, and we have to react quickly to keep up with events as they unfold. I have a sense that the respiratory research community would like to remain a cohesive group, and my commitment to the CTS is to represent this view to the CIHR. 


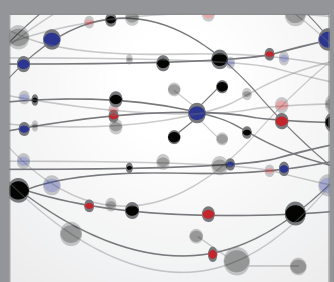

The Scientific World Journal
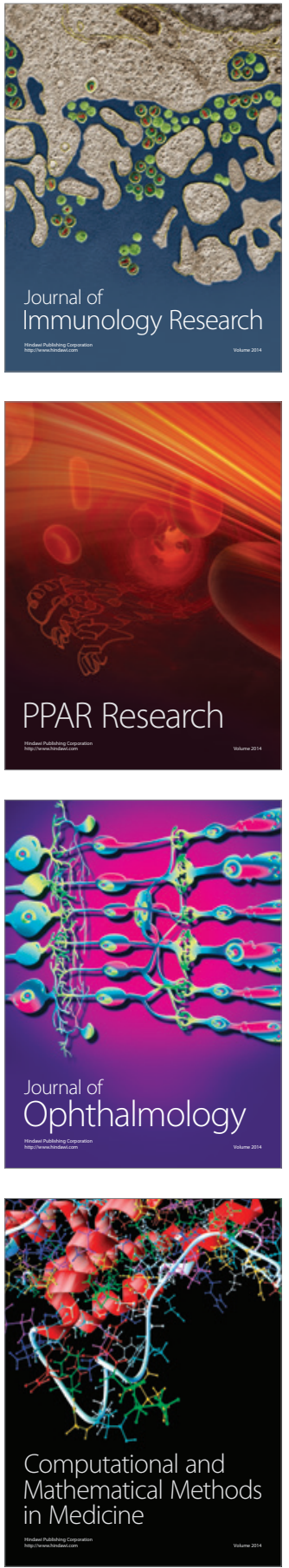

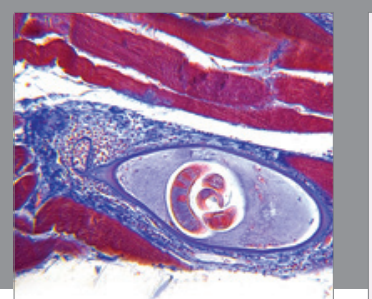

Gastroenterology Research and Practice

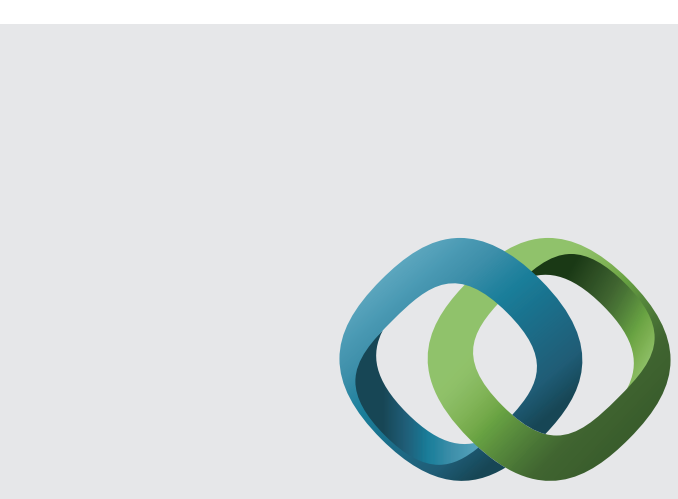

\section{Hindawi}

Submit your manuscripts at

http://www.hindawi.com
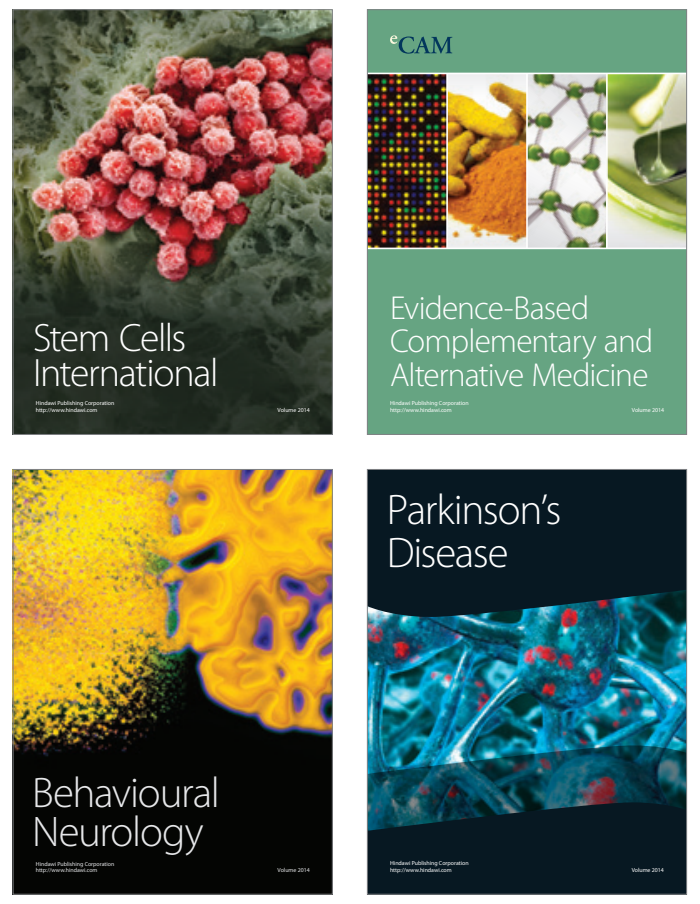
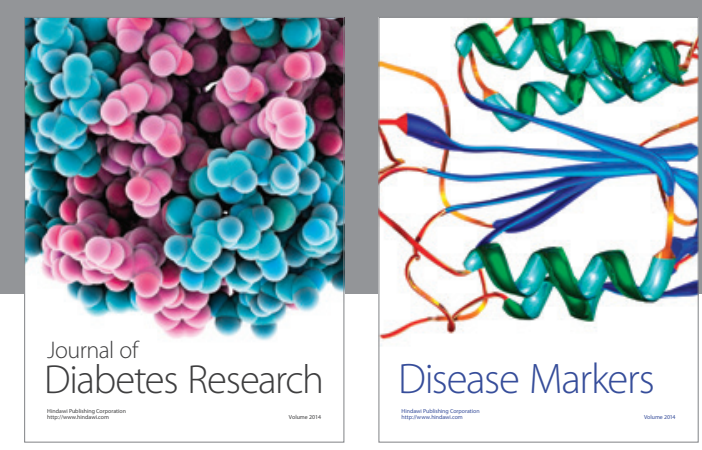

Disease Markers
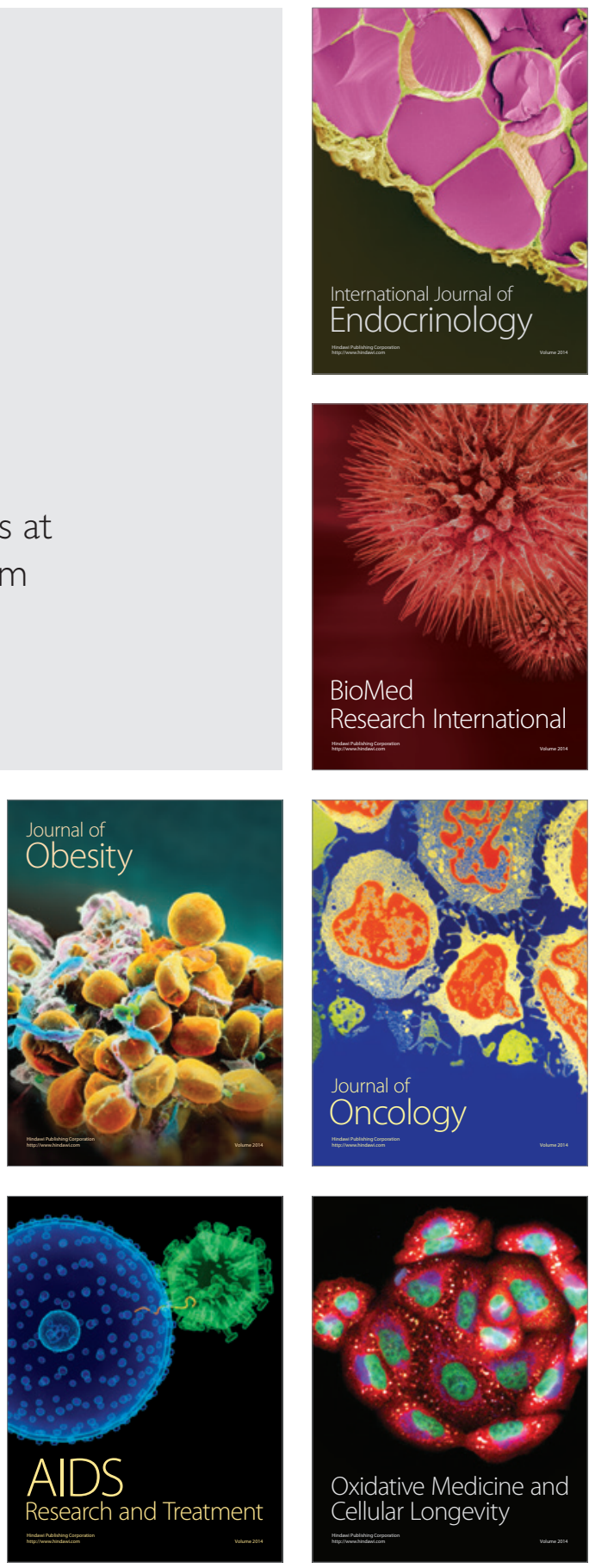